\title{
PECULIARITIES OF THE STRUCTURE OF WELDED ALUMINUM ALLOY JOINTS
}

\author{
N. B. Pugacheva*, N. S. Michurov, E. B. Trushina \\ Institute of Engineering Science, Ural Branch of the Russian Academy of Sciences, 34 Komsomolskaya st., \\ Ekaterinburg, Russian Federation

\begin{abstract}
*Corresponding author. E-mail: nat@imach.uran.ru ; address for correspondence: ul. Komsomolskaya 34, 620049, Ekaterinburg, Russian Federation. Tel.:+7 343 3753591; fax: +7 3433745330.
\end{abstract}

The paper presents results of studying the structure, distribution of chemical elements and microhardness values across the width of welded joints of AMg6 aluminum alloy sheets after pulsed arc welding and 01420 ones after laser welding. Results of studying the variation in the values of the contact elastic modulus through the welded joint of the AMg6 alloy and the strength of the 01420 alloy joint are discussed, as well as results of studying the granular structure of the alloys by the EBSD method.

Keywords: aluminum alloy, welding, electric arc, laser, weld, heat-affected zone, microstructure, intermetallic, microhardness.

DOI: $10.17804 / 2410-9908.2015 .5 .058-071$

\section{References}

1. Kolachev B.A., Yelagin V.I., Livanov V.A. Metallovedenie i termicheskaya obrabotka metallov [Metal Science and Heat Treatment of Metals]. M, MISIS Publ., 2001, 416 p. (In Russian).

2. Mashinostroenie. Entsiklopediya. T. II-3: Tsvetnye metally i splavy. Kompozitsionnye metallicheskie materialy [Fridlyander I.N., ed. Mechanical Engineering. Vol. II-3: Nonferrous Metals and Alloys. Composite Metal Materials]. M, Mashinostroenie Publ., 2001, 880 p. (In Russian).

3. Fridlyander I.N. Modern Aluminum and Magnesium Alloys and Composite Materials Based on Them. Metal Science and Heat Treatment, 2002, vol. 44, iss 7, pp. 292-296. DOI: 10.1023/A: 1021255804324.

4. Hatch J.E., ed. Aluminium. Properties and Physical Metallurgy. Ohio, American Society for Metals, 1984.

5. Turkin V.D., Rumyantsev M.V. Struktura i svoistva tsvetnykh metallov $i$ splavov [Structure and Properties of Nonferrous Metals and Alloys], M., Metallurgizdat, 1947, 440 p. (In Russian).

6. Dorokhina L.N., Tauzhnyanskaya Z.A. Legkie tsvetnye metally i splavy. Spravochnik. T. 2 [Light Nonferrous Metals and Alloys. Reference book. Vol. 2]. M., FGUP TSNIIEItsvetmet, 2001, 480 p. (In Russian).

7. Orishich A.M., Cherepanov A.N., Shapeev V.P., Pugacheva N.B. Nanomodifitsirovanie svarnykh soedineniy pri lazernoi svarke metallov $i$ splavov [Nanomodification of welded joints in Laser Welding of Metals and Alloys]. Novosibirsk, SO RAN Publ., 2014, 252 p. (In Russian).

8. Saraev Yu.N., Golikov N.I., Dmitriev V.V., Sannikov I.I., Bezborodov V.P., Grigorieva A.A. Studying the effect of adaptive pulsed arc welding on the mechanical properties and residual stresses of 09G2S steel welded joints. Obrabotka metallov, 2013, no. 3 (60), pp. 19-24. (In Russian).

9. Amit Kumar Barik. Joining of dissimilar materials using Nd: YAG laser welding. A Thesis of Bachelor of Technology (Mechanical Engineering), Rourkela, India, National Institute of Technology, 2010, $48 \mathrm{p}$.

10. Buddery A., Dargusch M., StJohn D., Drennan J., Nabulsi S. Laser Welding of Titanium and its Alloys for Medical Applications: Current Knowledge and Future Direction. Materials Science Forum, 2009, vols 618-619, pp. 291-294. DOI: 10.4028/www.scientific.net/MSF.618-619.291. 
11. Pugacheva N.B., Trushina E.B., Antenorova N.P. Effect of laser processing on the microstructure of a structural low-carbon steel. Russian Metallurgy (Metally), 2014, vol. 2014, iss. 7, pp 569-575. DOI: 10.1134/S0036029514070118.

12. Pugacheva N.B., Vichuzhanin D.I., Antenorova N.P. The strength and nature of failure of VT5-1 titanium alloy welded joints. Deformatsiya i razrushenie materialov, 2014, no. 3, pp. 33-38. (In Russian).

13. Grigoriants A.G., Shiganov I.N. Lazernaya tekhnika i tekhnologiya. Kn. 5: Lazernaya svarka metallov [Laser Technology and Engineering. Book 5: Laser Welding of Metals]. M., Vyssh. Shk. Publ., 1988, 206 p. (In Russian).

14. Zabelin A.M., Orishich A.M., Chirkov A.M. Lazernye tekhnologii mashinostroeniya [Laser Technologies in Mechanical Engineering]. Novosibirsk, NGU Publ., 2004, 156 p. (In Russian).

15. Oliver W.C., Phar G.M. An improved technique for determining hardness and elastic modulus using load and displacement sensing indentation experiments. Journal of Materials Research, 1992, vol. 7, iss. 6, pp. 1564-1583. DOI: 10.1557/JMR.1992.1564.

16. Fedosov S.A., Pešek L. Opredelenie mekhanicheskikh svoistv materialov mikroindentirovaniem: sovremennye zarubezhnye metodiki [Determining Mechanical Properties of Materials by Microindentation: Modern Foreign Methods]. Moscow, Faculty of Physics of MSU, 2004. (In Russian).

17. Bulychev S.I. Relation between the reduced and unreduced hardness in nanomicroindentation tests. Technical Physics, 1999, vol. 44, iss. 7, pp. 775-781.

18. Smirnov S.V., Pugacheva N.B., Myasnikova M.V., Smirnova E.O. Structural heterogeneity of an aluminum alloy welded joint and simulation of its elastic deformation. Fizicheskaya mezomekhanika, 2014, no. 1, pp. 51-56. (In Russian).

19. Pugacheva N.B., Trushina E.B., Pugacheva E.I. Laser welding of the Ti-5Al-2.5Sn titanium alloy. Voprosy materialovedeniya, 2013, no. 2 (74), pp. 83-92. (In Russian). 
Подана в журнал: 03.09.2015

УДК 620.18.186

DOI: $10.17804 / 2410-9908.2015 .5 .058-071$

\title{
ОСОБЕННОСТИ СТРОЕНИЯ СВАРНЫХ СОЕДИНЕНИЙ АЛЮМИНИЕВЫХ СПЛАВОВ
}

\author{
Н. Б. Пугачева*, Н. С. Мичуров, Е. Б. Трушина \\ Федеральное государственное бюджетное учреждение науки Институт машиноведения \\ Уральского отделения Российской академии наук, ул. Комсомольская, 34, Екатеринбург, Российская Федерация \\ *Ответственный автор. Электронная почта: nat@imach.uran.ru; адрес для переписки: ул. Комсомольская, 34, \\ 620049, Екатеринбург, Российская Федерация. Телефон: +7 (343) 375-35-91; факс: +7 (343) 374-53-30
}

Представлены результаты исследований строения, характера распределения химических элементов и значений микротвердости по ширине зон сварных соединений листов алюминиевых сплавав марок АМг6 после импульсно-дуговой сварки и 01420 после лазерной сварки. Приведены результаты исследований изменения значений контактного модуля упругости по сварному соединению сплава АМг6 и прочности соединения сплава 01420, а также зеренного строения сплавов методом EBSD.

Ключевые слова: алюминиевый сплав, сварка, электрическая дуга, лазер, сварной шов, зона термического влияния, микроструктура, интерметаллид, микротвердость.

\section{1. Введение}

Алюминиевые сплавы отличаются уникальным сочетанием технологических и эксплуатационных свойств: во-первых, малые значения удельного веса этих материалов в сочетании с высокими механическими свойствами делают их весьма привлекательными в качестве конструкций авиакосмической техники, во-вторых, высокие значения тепло- и электропроводности определяют их применение в электроэлектронике, в третьих, хорошая технологическая обрабатываемость (литейные свойства и способность легко пластически деформироваться) позволяют получать конструкции практически любой формы [1-3]. Кроме этих свойств алюминиевые сплавы обладают высокой коррозионной стойкостью, что позволяет их использовать в различных агрессивных средах.

Широкое применение в качестве элементов конструкций нашли алюминиевые сплавы системы Al-Mg - магналии, которые относятся к группе термически неупрочняемых алюминиевых деформируемых сплавов $[1,4,5]$. Из этих сплавов изготавливают все виды полуфабрикатов: листы, плиты, прессованные изделия (прутки, профили, панели, трубы, поковки и штамповки, проволоку заклёпочную и сварочную и др.). Они имеют относительно невысокие прочностные характеристики по сравнению с термически упрочняемыми алюминиевыми сплавами, но при этом отличаются высокими показателями пластичности и коррозионной стойкости, особенно в условиях морской атмосферы, а также хорошо свариваются плавлением. Магний способствует повышению прочностных свойств полуфабрикатов, кроме того, с повышением содержания магния коэффициент трещинообразования при сварке уменьшается $[1,6]$. Однако в связи с увеличением температурного интервала плавления и повышением концентрации водорода, с ростом содержания магния пористость сварных соединений возрастает. Для улучшения свойств сплавы системы $\mathrm{Al}-\mathrm{Mg}$ легируют марганцем $(0,4$ 0,6 мас. \%) и титаном (0,06 мас. \%), которые упрочняют твердый раствор и играют роль модификатора литой зеренной структуры при кристаллизации, что особенно важно при формировании сварных швов, поскольку способствует уменьшению склонности сплавов к кристаллизационным трещинам [6]. 
Сверхлегкие алюминиевые системы Al-Mg-Li, такие как сплава 01420, благодаря сочетанию низкой плотности, высокого модуля упругости, коррозионной стойкости и хорошей свариваемости, применяются в авиационной технике, например в качестве материала для обшивки фюзеляжа самолетов. Введение лития привело к тому, что в отличие от сплавов системы Al-Mg, эти сплавы термически упрочняются при старении при температуре $120{ }^{\circ} \mathrm{C}$ за счет выделения дисперсных частиц $\delta^{\prime}-$ фазы $\mathrm{Al}_{3} \mathrm{Li}$, упорядоченной по типу $L 1_{2}$. В отечественном самолетостроении для соединения листовых конструкций из таких сплавов традиционно используют метод клепки. Несомненный практический интерес представляют разработки, позволяющие использовать сварку для получения прочных конструкций.

Технология сварки алюминия и его сплавов имеет ряд особенностей по сравнению со сваркой сталей из-за существенных отличий свойств этих материалов. Алюминий и его сплавы имеет теплопроводность примерно в 5 раз выше, чем у сталей, поэтому тепло от места сварки интенсивно отводится в свариваемые детали, что требует повышенного тепловложения по сравнению со сваркой сталей $[1,2]$. Это крайне нежелательно, поскольку, алюминий характеризуется низкой температурой плавления, причем прочность его при нагреве резко снижается. Таким образом, вероятность «прожога» или расплавления детали при сварке алюминия значительно выше, чем при сварке стали. Кроме того, алюминий имеет значительную литейную усадку (в 2 раза больше, чем у стали), поэтому при кристаллизации металла сварочной ванны в нем развиваются значительные внутренние напряжения и деформации, приводящие к образованию «горячих трещин».

В настоящее время из всех известных способов для сварки алюминия чаще всего применяются следующие три: ручная, аргоно-дуговая, полуавтоматическая [7-9]. Перспективным является использование лазерной сварки, характеризующейся рядом преимуществ: это, прежде всего, высокой плотностью мощности излучения, которая обеспечивает локальность проплавления и формирование узкого шва достаточно большой глубины с коэффициентом формы более 2,5; сверхвысокие скорости нагрева и охлаждения после лазерного воздействия сокращают ширину зон термического влияния, а также снижают степень газонасыщения сплавов, особенно при выполнении защиты зон сварочной ванны и термического влияния инертными газами [7,9-11]. При сварке сталей и титановых сплавов удалось получить сварные соединения, прочность которых выше, чем у соединяемых материалов $[2,11,12]$. Однако даже при лазерной сварке существуют определенные проблемы получения прочных соединений алюминиевых сплавов. Это, прежде всего, быстрое образование оксидов на поверхности, поглощение газов из окружающей среды, высокая отражающая способностью алюминиевых сплавов $[13,14]$. Структура и свойства лазерных сварных соединений сверхлегких сплавов системы $\mathrm{Al}-\mathrm{Mg}-\mathrm{Li}$ в настоящее время мало изучены, а имеющиеся экспериментальные данные весьма противоречивы.

Целью настоящей работы является изучение особенностей формирования, структуры и оценка прочности сварных соединений листовых заготовок из сплава АМг6, полученных импульсно-дуговой сваркой, и сплава 01420, полученных сваркой с помощью $\mathrm{CO}_{2}$-лазера.

\section{2. Материалы и методика эксперимента}

В качестве объектов исследования использованы листовые заготовки сплава АМг6 толщиной 3 мм, соединение которых проводилось импульсно-дуговой сваркой ${ }^{1}$ по режимам, указанным в табл. 1, и листовые заготовки из сплава 01420 толщиной 1,5 мм, сваренные $\mathrm{CO}_{2}$ лазером непрерывного действия ${ }^{2}$ мощностью излучения $\mathrm{P}=3$ кВт при скорости сварки $\mathrm{V}=6,3$ м/мин. Для защиты поверхности сварочной ванны и перегретых околошовных зон

\footnotetext{
${ }^{1}$ Импульсно-дуговую сварку проводили в Институте физики прочности и материаловедения СО РАН г. Томск под руководством проф. д.т.н. Ю.Н. Сараева.

2 Лазерную сварку проводили в Институте теоретической и прикладной механики им. С. А. Христиановича Сибирского отделения РАН под руководством проф. д.ф.-м.н. А.М. Оришича.
} 
применяли гелиевую атмосферу при подаваемом давлении 5,5 атм. Поверхность шлифов, изготовленных по поперечному резу шва, исследовали методами оптической металлографии на микроскопе NEOPHOT 21. Определение величины зерна проведено в соответствии с требованиями ГОСТ 21073.1-75 «Металлы цветные. Определение величины зерна методом сравнения со шкалой микроструктур».

Таблица 1 - Режимы дуговой сварки и геометрические показатели сварных соединений листов сплава АМг6

\begin{tabular}{|c|c|c|c|}
\hline \multirow{2}{*}{\begin{tabular}{c}
\multirow{2}{*}{ обр } \\
образца
\end{tabular}} & Режим сварки & \multicolumn{2}{|c|}{ Ширина, мм } \\
\cline { 3 - 4 } & Стационарный & 3 ЗВ & 3СШ \\
\hline 1 & Импульсный & 32 & 5,5 \\
\hline 2 & Импульсный каплеперенос с модуляцией & 14 & 3,5 \\
\hline 3 & \multicolumn{2}{|c}{} \\
\hline
\end{tabular}

Микротвердость по Виккерсу определяли на приборе LEICA VMHT при нагрузках 0,25 и 0,5 Н. Микрорентгеноспектральный анализ осуществляли на приборе TESCAN VEGA II XMU с приставкой OXFORD. Локальность анализа 1 мкм при погрешности 5 \% от измеряемой концентрации. Структура сплавов и материала полученных сварных соединений изучена также с применением методики анализа картин дифракции обратноотраженных электронов (EBSD) с использованием программного комплекса Aztec на TESCAN VEGA II XMU с приставкой Oxford NKLNordlysF+.

Определение значений контактного модуля упругости и работы пластической деформации проводили методом микроиндентирования с использованием системы для измерения микротвердости FISCHERSCOPE HM2000 XYm при нагрузке 100 мН и выдержке 15 с по методикам авторов работ [15-17]. Значение полной работы, затраченной на вдавливание индентора, определяли площадью под кривой нагружения (рис. 1), значение работы сил упругого последействия (релаксации) - площадью под кривой разгрузки, а работы, затраченной на остаточное формоизменение материала при вдавливании индентора, - площадью, ограниченной кривыми нагружения и разгрузки.

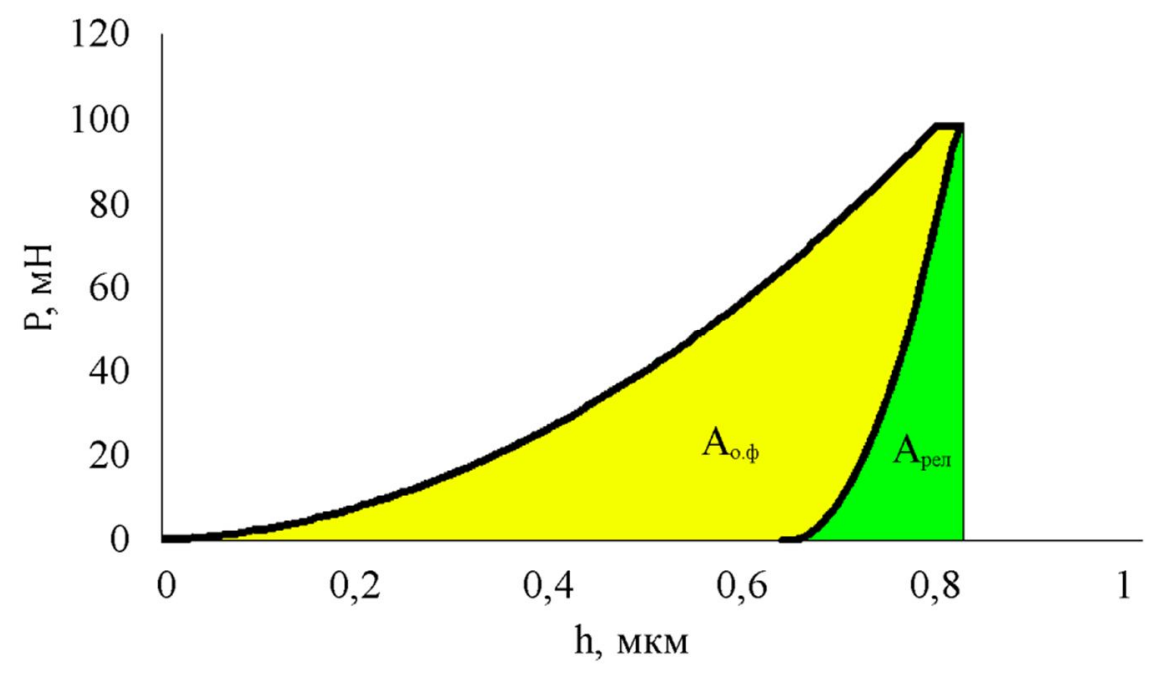

Рис. 1. Схема расчетов работы остаточного формоизменения $\left(\mathrm{A}_{\text {о.ф. }}\right)$ и работы сил упругого последействия - релаксации ( $\left.\mathrm{A}_{\text {рел. }}\right)$

Прочность сварных соединений сплава 01420, а именно значения временного сопротивления отрыву $\sigma_{в}$, оценивали по результатам испытаний на статическое растяжение на сер- 
вогидравлической испытательной машине INSTRON $8801^{3}$ (скорость растяжения составляла 1 мм/мин). Образцы для испытаний вырезали из участков со сварными швами таким образом, чтобы швы располагались в средней части рабочей длины образцов.

\section{3. Результаты исследований и их обсуждение}

\section{1. Сварной шов листа из сплава АМг6, полученный индукционно-дуговой сваркой}

Промышленные сплавы системы $\mathrm{Al}-\mathrm{Mg}$ в соответствии с равновесной диаграммой состояния представляют собой $\alpha$-твердый раствор на основе алюминия с частицами второй фазы $\mathrm{Al}_{3} \mathrm{Mg}_{2}$ [1]. Кроме того, в сплавах могут присутствовать фазы, содержащие марганец $\left(\mathrm{Al}_{6} \mathrm{Mn}\right)$ и кремний $\mathrm{Mg}_{2} \mathrm{Si}[1,3]$. Если в основном сплаве и зоне термического влияния (далее по тексту 3ТВ) хорошо различимы зерна $\alpha$-твердого раствора на основе алюминия, то в материале сварного шва (далее по тексту ЗСШ) выявляется дендритная структура, характерная для литых алюминиевых сплавов (рис. 2). Весьма мелкодисперсное строение дендритов в зоне ЗСШ свидетельствует о высоких скоростях кристаллизации алюминиевого сплава. Локальный микрорентгеноспектральный анализ показал, что оси дендритов содержат в среднем 3,4 мас. \% Mg, а междендритные пространства - 5, 6 \% этого элемента.

С точки зрения прочности сварного соединения важно определить степень роста зерна в ЗТВ. Для этого в соответствии с требованиями ГОСТ 21073.1 - 75 определяли балл и средний диаметр зерна (d). Все исследованные режимы индукционно-дуговой сварки показали незначительное увеличение размеров зерен в ЗТВ и материале сварного ЗСШ (табл. 2 и рис. 3).

При металлографическом травлении поперечного реза сварных соединений листа сплава АМг6 весьма сложно оказалось выявить зеренное строение, особенно в материале ЗСШ, характеризующемся дендритным строением (рис. 2). Для наиболее точного определения размера зерна во всех зонах исследованных соединений был использован метод EBSD (рис. 3). Следует отметить, что режим сварки с модуляцией каплепереноса обеспечил наиболее дисперсное строение материала СШ, сопровождающееся максимально равномерным распределением элементов. По данным локального микрорентгеноспектрального анализа, частицы интерметаллидов в исследованном сплаве можно разделить на два вида: темные частицы на рис. 4 a по составу соответствуют соединению $\mathrm{Al}_{3}(\mathrm{Mg}, \mathrm{Si})_{2}$, а светлые $-\mathrm{Al}_{6}(\mathrm{Mn}, \mathrm{Fe})$. Размер этих частиц в материале СШ в $2-3$ раза меньше по сравнению с ЗТВ и основным сплавом, что обусловлено частичным или полным их растворением в сварочной ванне. На рис. 4 б показан характер распределения элементов по ширине сварного соединения.

Таблица 2 - Определение величин зерна по ГОСТ 21073.1-75 «Металлы цветные. Определение величины зерна методом сравнения со шкалой микроструктур»

\begin{tabular}{|c|c|c|c|c|c|c|}
\hline \multirow{2}{*}{$\begin{array}{c}\text { № } \\
\text { образца }\end{array}$} & \multicolumn{2}{|c|}{ Основа } & \multicolumn{2}{c|}{ ЗТВ } & \multicolumn{2}{c|}{ ЗТШ } \\
\cline { 1 - 7 } & $\begin{array}{c}\text { Балл } \\
\text { зерна }\end{array}$ & $\mathrm{d}, \mathrm{mм}$ & $\begin{array}{c}\text { Балл } \\
\text { зерна }\end{array}$ & $\mathrm{d}, \mathrm{Mм}$ & $\begin{array}{c}\text { Балл } \\
\text { зерна }\end{array}$ & $\mathrm{d}, \mathrm{mм}$ \\
\hline 1 & 4 & 0,088 & $5-6$ & $0,062-0,044$ & 7 & 0,031 \\
\hline 2 & 4 & 0,088 & $5-6$ & $0,062-0,044$ & 7 & 0,031 \\
\hline 3 & 4 & 0,088 & 5 & 0,062 & 6 & 0,044 \\
\hline
\end{tabular}

\footnotetext{
${ }^{3}$ Испытания проведены на оборудовании Центра коллективного пользования ИМАШ УрО РАН к.т.н. Д. И. Вичужаниным
} 
open-access jürnal

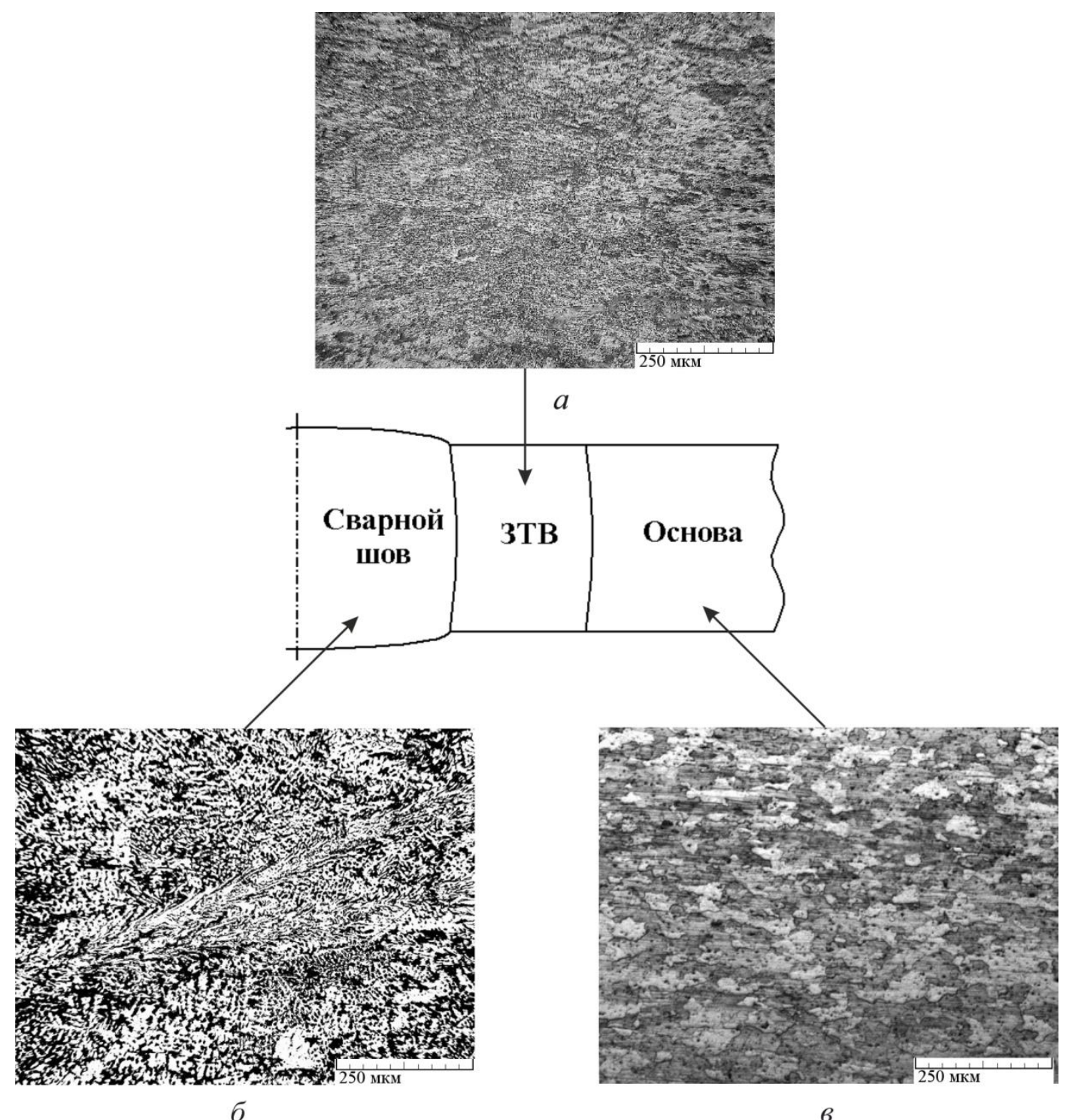

Рис. 2. Микроструктура зон сварного шва листа сплава АМг6, полученного импульснодуговой сваркой: $a$ - зона термического влияния; $\sigma$ - сварной шов; $\boldsymbol{\theta}$ - материал основы

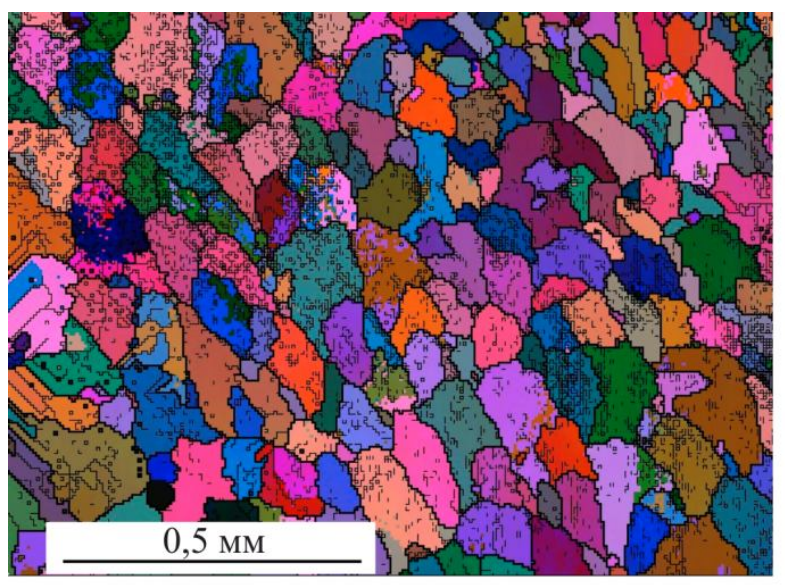

$a$

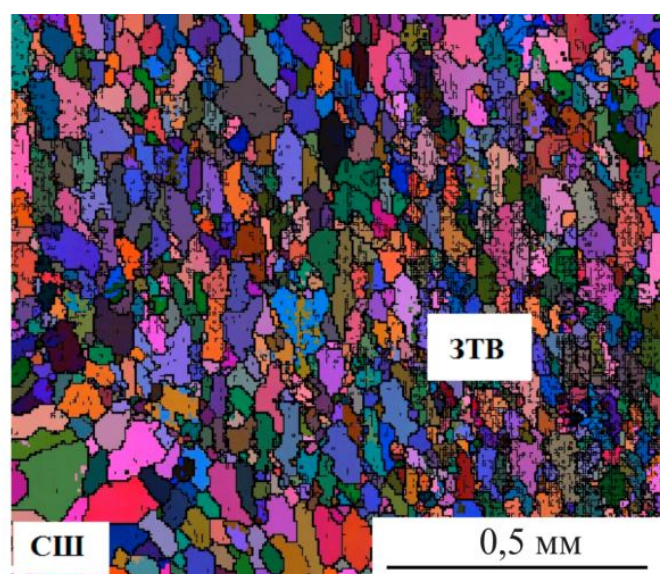

б

Рис. 3. Зеренная структура сплава АМг6 в зоне сварного шва (a) и зоне термического влияния (б) 


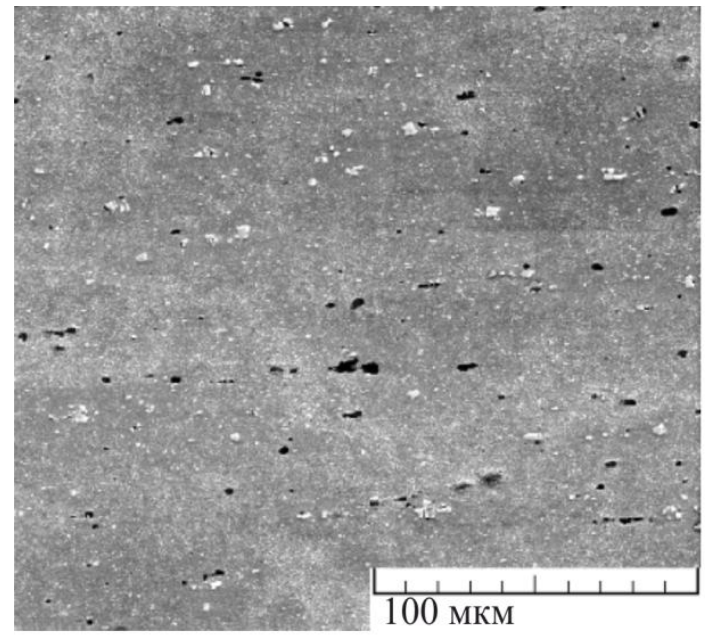

$a$

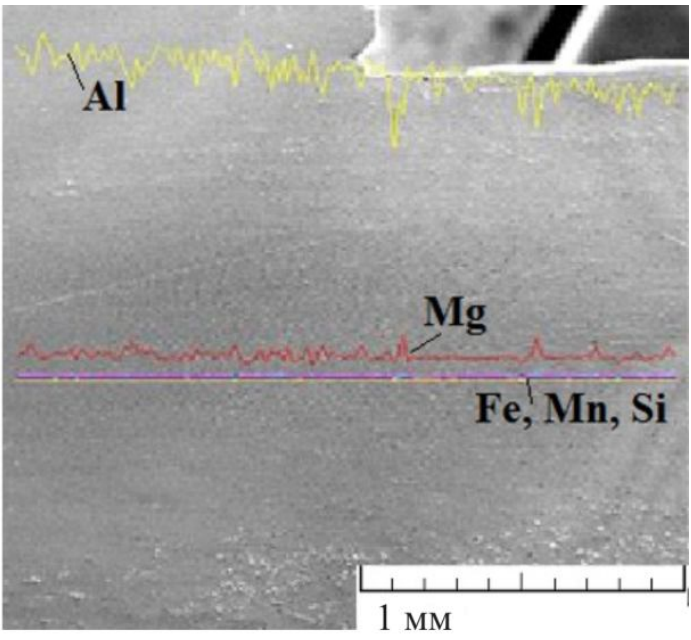

6

Рис. 4. Изображение шлифа АМг6 во вторичных электронах: $a$-распределение интерметаллидов в зоне сварного шва (темные частицы $\mathrm{Al}_{3}(\mathrm{Mg}, \mathrm{Si})_{2}$, светльле - $\mathrm{Al}_{6}(\mathrm{Mn}, \mathrm{Fe})$; $\sigma$ - характер распределения химических элементов по ширине сварного соединения листа сплава АМг6

В табл. 3 представлены результаты измерения микротвердости исследуемых образцов сплава АМг6. Для сравнения степени структурной однородности материала в области соединений, полученных по разным режимам, для каждого исследуемого образца был проведен расчет отношения средних значений твердости материала ЗТВ и ЗСШ к средней твердости основы, результаты представлены в табл. 4. При модуляции каплепереноса различия значений твердости минимальны, т.е. можно говорить о том, что сварной шов, полученный по режиму 3 , более однороден, что несомненно благоприятно скажется на его прочности.

Известно $[17,18]$, что модуль упругости не является структурнозависимой величиной, поэтому сложно было ожидать значимых изменений в значениях этого параметра в материале сварных швов. Некоторые колебания значений контактного модуля упругости (см. табл. 5), скорее всего, связаны с микропористостью, которую, как было показано ранее $[11,12,18-20]$, не удается избежать при лазерной сварке даже при защите сварочной ванны инертными атмосферами.

Таблица 3 - Распределение значений микротвердости (HV 0,05) по сварному шву на $1 / 2$ толщины листа

\begin{tabular}{|c|c|c|c|c|c|c|c|c|c|}
\hline \multirow{2}{*}{$\begin{array}{c}\text { № } \\
\text { образца }\end{array}$} & \multicolumn{3}{|c|}{ Основа } & \multicolumn{3}{c|}{ ЗТВ } & \multicolumn{3}{c|}{ ЗСШ } \\
\cline { 2 - 10 } & $\min$ & $\max$ & $\mathrm{cp.}$ & $\min$ & $\max$ & $\mathrm{cp.}$ & $\min$ & $\max$ & сp. \\
\hline 1 & 60,8 & 86,0 & 75,8 & 102 & 117 & 107,6 & 82,7 & 130 & 108,9 \\
\hline 2 & 94,3 & 97,0 & 95,9 & 107 & 123 & 113 & 99,7 & 126 & 112,1 \\
\hline 3 & 94,2 & 113 & 106,0 & 107 & 121 & 116 & 94,1 & 125 & 107,9 \\
\hline
\end{tabular}

Таблица 4 - Твердость зоны термического влияния и сварного шва относительно твердости основы

\begin{tabular}{|c|c|c|}
\hline \multirow{2}{*}{$\begin{array}{c}\text { № } \\
\text { образца }\end{array}$} & \multicolumn{2}{|c|}{ Отношение, \% } \\
\cline { 2 - 3 } & ЗТВ & 3СШ \\
\hline 1 & 142,0 & 143,7 \\
\hline 2 & 120,3 & 119,4 \\
\hline 3 & 109,4 & 101,8 \\
\hline
\end{tabular}


Таблица 5 - Распределение значений модуля Юнга и работы пластической деформации по сварному шву

\begin{tabular}{|c|c|c|c|c|c|c|}
\hline \multirow{2}{*}{$﹎{\text { o.бр }}$} & \multicolumn{3}{|c|}{$\mathrm{E}$, ГПа } & \multicolumn{3}{c|}{$\mathrm{A}_{\text {о.ф., мкДж }}$} \\
\cline { 2 - 7 } & $\min$ & $\max$ & $\mathrm{cp}$. & $\min$ & $\max$ & $\mathrm{cp}$. \\
\hline 1 & 83,41 & 94,60 & 90,88 & 0,0506 & 0,0555 & 0,0535 \\
\hline 2 & 82,74 & 99,11 & 89,70 & 0,0455 & 0,0586 & 0,0511 \\
\hline 3 & 82,66 & 94,31 & 91,36 & 0,0429 & 0,0560 & 0,0514 \\
\hline
\end{tabular}

Таким образом, выполненные исследования показали, что при импульсно-дуговой сварке листа из сплава АМг6 происходит формирование достаточно однородного по структуре сварного соединения, причем дополнительное использование импульсного каплепереноса позволяет получить максимально однородное распределение значений микротвердости по ширине всех зон сварного соединения, что благоприятно скажется на его прочности. Существенной рекристаллизации в материале 3ТВ не наблюдалось: по размеру зерна материала 3ТВ отличаются от основного сплава всего на 1-2 балла, что не должно существенно снизить прочность этой зоны сварного соединения.

\section{2. Сварной шов листа из сплава 01420, полученный лазерной сваркой}

Сплав 01420 относится к термически упрочняемым деформируемым алюминиевым сплавам. Основу сплава составляет $\alpha$-твердый раствор легирующих элементов (главным образом $\mathrm{Li}$ и $\mathrm{Mg}$ ) в алюминии, зерна которого вытянуты вдоль направления прокатки, их размер составляет от 40 до 150 мкм в длину и от 10 до 20 мкм в ширину (рис. 5 a). По границам зерен в виде сплошных строчек расположены частицы $\mathrm{S} 1$-фазы $\mathrm{Al}_{2} \mathrm{MgLi}$ размером от 0,6 до 3 мкм. Магний в сплаве образует соединение с кремнием $\mathrm{Mg}_{2} \mathrm{Si}[1,3]$, которое присутствует в виде единичных частиц темно-серого, почти черного, цвета, хаотично расположенных по объему сплава и имеющих размеры 0,1-0,3 мм [18]. Более мелкие включения неправильной формы размерами 25х50 мкм содержат железо, которое образует интерметаллид $\mathrm{Fe}_{2} \mathrm{Al}_{2}$ содержанием железа от 31 до 35 мас. \%. В сплаве присутствуют также светлые включения, которые содержат цирконий и в меньшем количестве титан - интерметаллид $\mathrm{Al}_{3}(\mathrm{Zr}, \mathrm{Ti})$. Tвёрдость сплава-основы составила 150-162 HV 0,05.

Ширина исследованных сварных швов в сплаве 01420 в поперечном сечении составила 1,0-1,2 мм, а зон термического влияния - 2,0 мм. Структурно ЗТВ практически не отличаются от сплава-основы (рис. $5 a$, б). Материал СШ имеет характерную для литого сплава разориентированную дендритную структуру в центре шва (рис. 5 г) и столбчатые дендриты вблизи зоны термического влияния (рис. 5 б). Микрорентгеноспектральный анализ показал, что оси дендритов обогащены алюминием, а в междендритных участках зафиксировано более высокое содержание магния за счет выделившихся мелкодисперсных частиц S1-фазы $\mathrm{Al}_{2} \mathrm{MgLi}$. Твёрдость материала СШ составила 108-123 HV 0,05, причём минимальные значения твёрдости наблюдаются в центральной части (рис. 5). Частиц $\mathrm{Al}_{3}(\mathrm{Zr}, \mathrm{Ti})$ и $\mathrm{Mg}_{2} \mathrm{Si}$ в материале СШ практически не обнаружено, что может быть связано с очень высокой скоростью кристаллизации расплава, при которой не успевают произойти все превращения, наблюдаемые в случае медленного охлаждения $[9,10]$.

В материале ЗТВ скоростные нагревы и охлаждения при лазерном воздействии не позволили осуществиться процессам рекристаллизации деформированного сплава. Узкая зона толщиной не более 0,1 мм рекристаллизованных зерен отмечается лишь на границе между ЗТВ и СШ (рис. 5 б). Значения твердости в ней уменьшились по сравнению с основой до 123-138 HV 0,05, причем минимальные значения соответствуют рекристаллизованной зоне (рис. 6). Частицы $\mathrm{Mg}_{2} \mathrm{Si}, \mathrm{FeAl}_{2}, \mathrm{Al}_{3}(\mathrm{Zr}, \mathrm{Ti})$ в ЗТВ практически не изменили своих размеров и формы по сравнению со сплавом-основой. 
opent-access journal

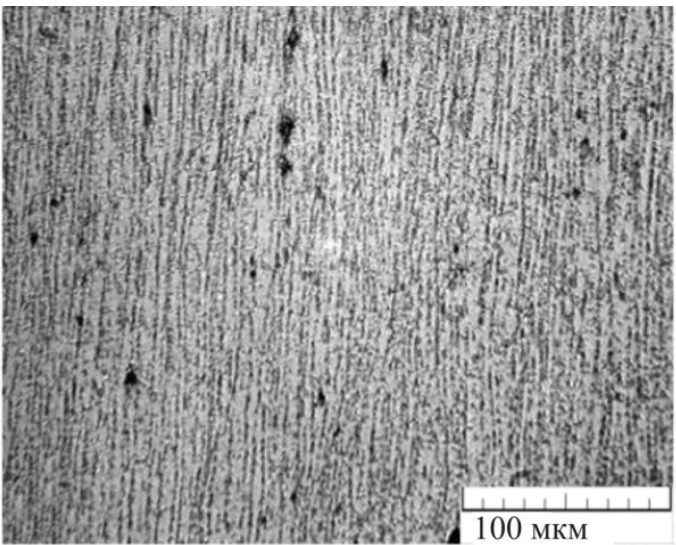

$a$

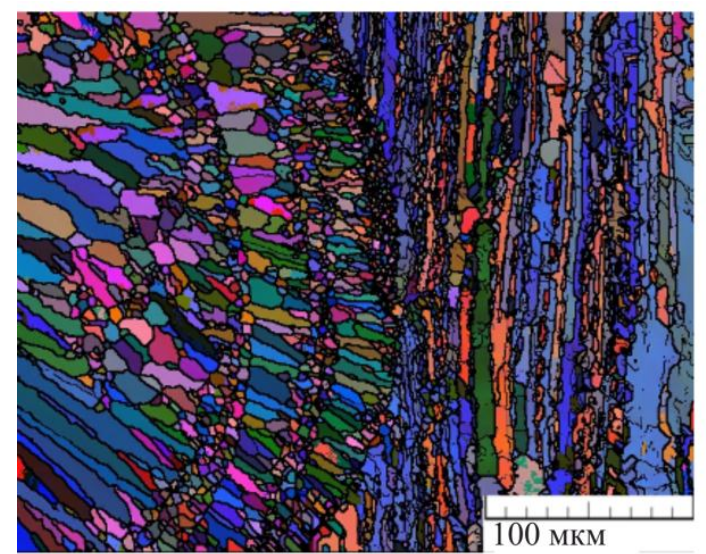

B

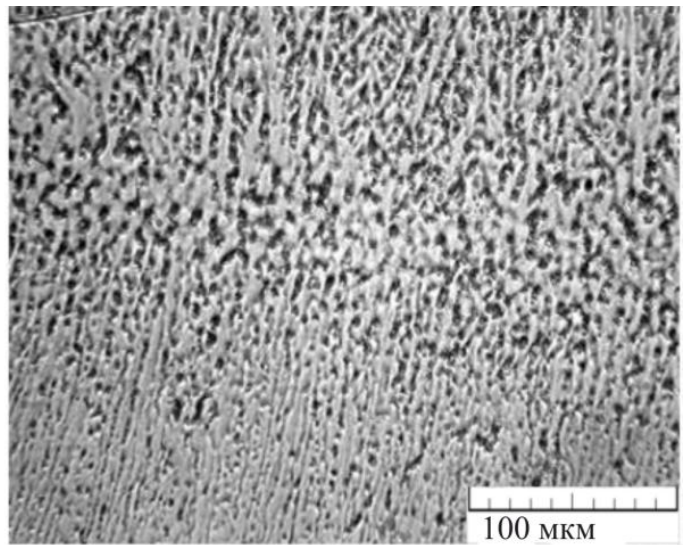

6

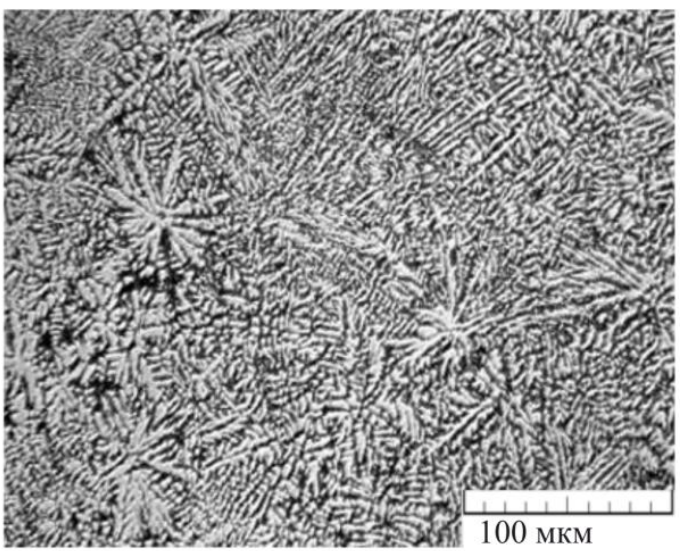

Рис. 5. Микроструктура сплава $01420(a)$, зоны термического влияния (б) и сварного шва $(b, 2) ; a, \sigma, 2$ - изображения в оптическом микроскопе; $в$ - зеренное строение прикорневой части шва при дифракции обратноотраженных электронов
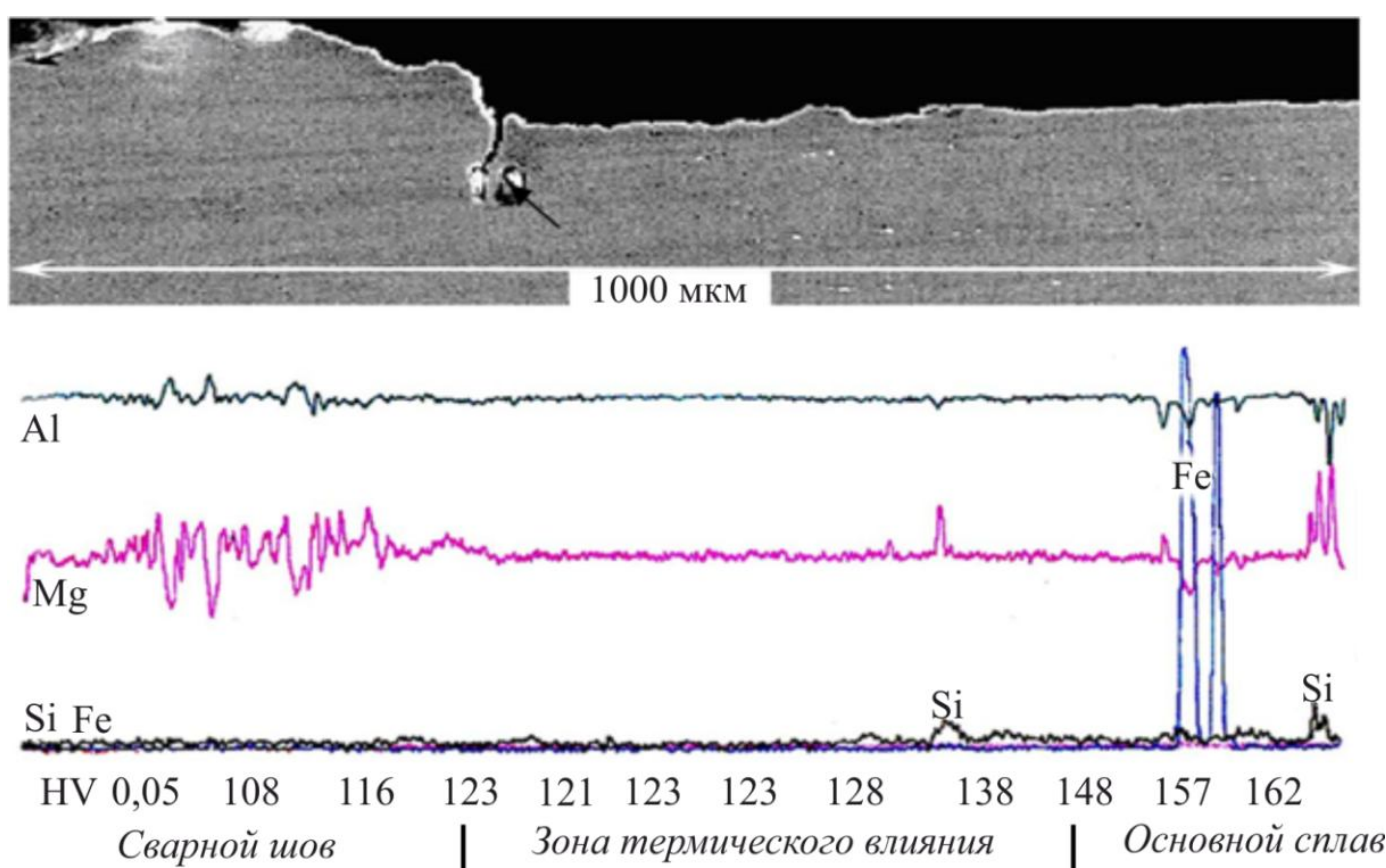

Рис. 6. Распределение элементов и значений микротвёрдости по ширине сварного соединения листа сплава 01420 
Формирование слоистой разнозернистой прослойки на границе СШ и ЗТВ в прикорневой зоне (рис. 5 в) связано с отличительными особенностями процессов динамического состояния расплава в образующейся при лазерном воздействии сварочной ванны. В отличие от импульсно-дуговой сварки, под воздействием лазерного луча происходит расплавление алюминиевого сплава с очень высокой скоростью. При этом сварочная ванна имеет форму, вытянутую вдоль направления движения луча, как показано на рис. 7. В головной части ванны расположен канал (кратер) - это область наиболее яркого свечения. Образование кратера происходит следующим образом: как только плотность мощности лазерного излучения достигает значений выше критической, нагрев металла идет со скоростью, значительно превышающей скорость отвода теплоты в основной металл за счет теплопроводности [13]. На поверхности жидкого металла под действием процессов вскипания металла и импульса отдачи паров образуется углубление. Увеличиваясь, оно образует канал, заполненный паром и окруженный жидким металлом. Давления пара оказывается достаточно для противодействия силам гидростатического давления и поверхностного натяжения, и полость канала не заполняется жидким металлом. При образовании канала над поверхностью металла появляется светящийся факел, состоящий из продуктов испарения, мелких выбрасываемых из ванны капель металла и из частиц конденсированного пара. При значительной скорости сварки факел отклоняется на $20-60^{\circ}$ в сторону, противоположную направлению сварки. Этот факел поглощает часть энергии луча и снижает его проплавляющую способность.

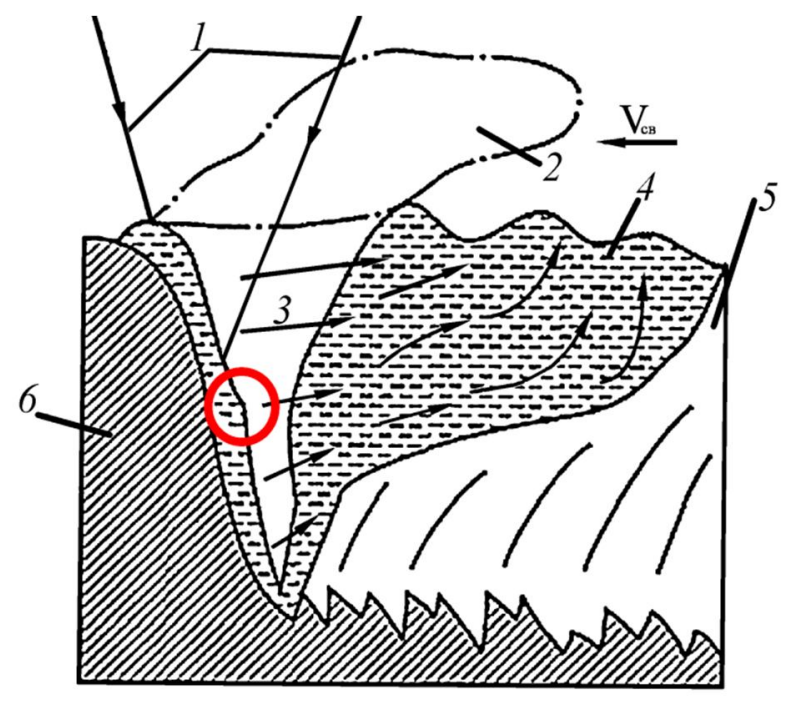

Рис. 7. Схема сварочной ванны при лазерной сварке [13]:

1 - лазерный луч; 2 - плазменный факел; 3 - парогазовый канал; 4 - хвостовая часть ванны;

5 - закристаллизовавшийся металл шва; 6 - свариваемый металл; $\mathrm{V}_{\text {св }}$ - скорость сварки

При некоторой скорости сварки форма канала приобретает динамическую устойчивость. На передней его стенке происходит плавление металла, на задней - затвердевание. Наличие канала способствует поглощению лазерного излучения в глубине свариваемого материала, а не только на его поверхности, за счет этого происходит так называемое "кинжальное проплавление", т.е. формируется узкий шов с большим соотношением глубины проплавления к ширине шва. Высокая теплопроводность алюминиевых сплавов обеспечивает одновременное протекание двух процессов: образования канала и поверхностного плавления. На передней стенке канала существует слой расплавленного металла, испытывающий постоянные возмущения. Здесь наблюдается характерное искривление передней стенки в виде ступеньки (красный кружок на рис. 7), которая периодически перемещается по высоте канала. Удаление расплавленного металла с передней стенки осуществляется при перемещении сту- 
пеньки сверху вниз. Перенос расплавленного металла из головной части ванны в хвостовую происходит по боковым стенкам в горизонтальном направлении. По мере углубления канала наблюдаются восходящие потоки движения расплава. В хвостовой части ванны расплавленный металл вихревыми потоками поднимается вверх и частично выносится на поверхность сварочной ванны. Скорость переноса расплава на три порядка выше скорости сварки. Очевидно, именно наличие таких вихревых потоков приводит к образованию слоистой структуры на границе материала СШ и ЗТВ в прикорневой зоне (рис. 5 в). Подобный плавный переход от материала основы к материалу СШ должен обеспечить прочность полученного соединения не уровне сплава.

Прочность материала сварного шва несколько ниже по сравнению со сплавом и составила 470 - 490 МПа (для сплава $01420 \sigma_{\mathrm{B}}=525 \mathrm{MПа),} \mathrm{что} \mathrm{обусловлено,} \mathrm{как} \mathrm{было} \mathrm{показано}$ ранее [18], внутренней микропористостью материла сварного шва. Для сплавов такого типа значения предела прочности должно быть не менее $440 \mathrm{MПа} \mathrm{[2],} \mathrm{т.е.} \mathrm{материал} \mathrm{СШ} \mathrm{удовле-}$ творяет требованию прочности сплава 01420.

\section{4. Заключение}

Импульсно-дуговая сварка листов сплава АМг6 толщиной 3 мм позволила получить сварные швы толщиной от 3,5 до 5,5 мм и твердостью $108-112$ HV 0,05. В материале зоны СШ выявлена дендритная структура, характерная для литых алюминиевых сплавов, имеющая весьма мелкодисперсное строение, что свидетельствует о высоких скоростях кристаллизации алюминиевого сплава в сварочной ванне. Локальный микрорентгеноспектральный анализ показал, что оси дендритов содержат в среднем 3,4 мас. $\% \mathrm{Mg}$, а междендритные пространства $-5,6 \%$ этого элемента.

Толщина ЗТВ составила 32 мм, при этом использование импульсного каплепереноса позволило уменьшить ее толщину до 14 мм. Твердость материала ЗТВ составила 108 - 116 HV 0,05 при значениях твердости сплава АМг6 95 - 108 HV 0,05. Использование метода анализа картин дифракции обратноотраженных электронов (EBSD) материала всех зон исследованных сварных соединений позволило с максимальной точностью определить размер зерна алюминиевого сплава АМг6, что весьма затруднено при металлографическом травлении, особенно для материала ЗСШ. Существенной рекристаллизации в материале ЗТВ не наблюдалось: по размеру зерна материала ЗТВ отличаются от основного сплава всего на 1-2 балла, что не должно существенно снизить прочность этой зоны сварного соединения.

При импульсно-дуговой сварке листа из сплава АМг6 происходит формирование достаточно однородного по структуре сварного соединения, причем дополнительное использование импульсного каплепереноса позволяет получить максимально однородное распределение значений микротвердости по ширине всех зон сварного соединения, что благоприятно скажется на его прочности.

Лазерная сварка листа толщиной 1,5 мм из сплава 01420 позволяет получать сварные швы, ширина которых составляет всего 1-1,2 мм, твердостью 108-123 HV 0,05, с мелкодисперсной дендритной структурой. Частиц $\mathrm{Al}_{3}(\mathrm{Zr}, \mathrm{Ti})$ и $\mathrm{Mg}_{2} \mathrm{Si}$ в материале ЗСШ не обнаружено, что обусловлено высокой скоростью кристаллизации расплава в сварочной ванне, при которой не успевают произойти все превращения, наблюдаемые в случае более медленного охлаждения алюминиевого сплава.

На границе со сварным швом образуются зоны термического влияния толщиной 2 мм, в которых не успевает пройти рекристаллизация. Первичная рекристаллизация с образованием новых равноосных зерен (микротвердость 123-128 HV 0,05) зафиксирована только непосредственно на границе с зоной переплава толщиной не более 0,1 мм.

Отличительной особенностью строения прикорневой зоны лазерного сварного шва листа сплава 01420 является формирование слоистой разнозернистой прослойки на границе с 3ТВ, обусловленной восходящими вихревыми потоками расплава в образующейся при ла- 
зерном воздействии сварочной ванны. Такое строение положительно влияет на прочность сварного соединения, устраняя резкий перепад свойств между материалом листа и ЗСШ. Прочность полученных сварных соединений составила 470-490 МПа, что удовлетворяет предъявляемому к таким сплавам требованию $\sigma_{\mathrm{B}} \geq 440$ МПа.

\section{Благодарность}

Авторы выражают благодарность к.т.н. Д.И. Вичужанину за помощь в проведении механических испытаний сварных швов сплава 01420.

Работа выполнена в соответствии с планом Фундаментальных научных исследований государственных академий наук на 2013 - 2020 годы по теме № 01201375906.

\section{Литература}

1. Колачев Б. А., Елагин В. И., Ливанов В. А. Металловедение и термическая обработка цветных металлов и сплавов. - М. : Изд-во МИСИС, 2001. - 416 с.

2. Машиностроение. Энциклопедия. Том II-3. Цветные металлы и сплавы. Композиционные металлические материалы / Под ред. И. Н. Фридляндера. - М. : Машиностроение, 2001. -880 c.

3. Фридляндер И. Н. Современные алюминиевые, магниевые сплавы и композиционные материалы на их основе // МиТОМ. - 2002. - № 7. - С. 24-29.

4. Алюминий: свойства и физическое металловедение: справ. изд. / пер. с англ. под ред. Дж. Е. Хэтча. - М. : Металлургия, 1989. - 422 с.

5. Туркин В. Д., Румянцев М. В. Структура и свойства цветных металлов и сплавов. М. : Металлургиздат, 1947. - 440 с.

6. Дорохина Л. Н., Таужнянская 3. А. Легкие цветные металлы и сплавы. Справочник. Т. 2. М. : ФГУП ЦНИИЭИцветмет, 2001. - 480 с.

7. Наномодифицирование сварных соединений при лазерной сварке металлов и сплавов / А. М. Оришич, А. Н. Черепанов, В. П. Шапеев, Н. Б. Пугачева. - Новосибирск : Изд-во СО РАН, 2014. $-252 \mathrm{c}$.

8. Исследование влияния адаптивной импульсно-дуговой сварки на механические свойства и остаточные напряжения сварных соединений стали марки 09Г2С / Ю. Н. Сараев, Н. И. Голиков, В. В. Дмитриев, И. И. Санников, В. П. Безбородов, А. А. Григорьева // Обработка металлов. - 2013. - № 3 (60). - С. 19-24.

9. Barik Amit Kumar. Joining of dissimilar materials using Nd: YAG laser welding : thesis. ... bachelor of technology : roll no. 10603066. - National Institute of Technology, Rourkela, India, 2010. $-48 \mathrm{p}$.

10. Laser Welding of Titanium and its Alloys for Medical Applications: Current Knowledge and Future Direction / A. Buddery, M. Dargusch, D. StJohn, J. Drennan, S. Nabulsi // Materials Science Forum. - 2009. - Vols 618-619. - P. 291-294. - DOI: 10.4028/www.scientific.net/MSF.618-619.291.

11. Pugacheva N. B., Trushina E. B., Antenorova N. P. Effect of laser processing on the microstructure of a structural low-carbon steel // Russian Metallurgy (Metally). - 2014. - Vol. 2014, iss. 7. - P. 569-575. - DOI: 10.1134/S0036029514070118.

12. Пугачева Н. Б., Вичужанин Д. И., Антенорова Н. П. Прочность и характер разрушения сварных швов титанового сплава ВТ5-1 // Деформация и разрушение материалов. - 2014. № 3. - Р. 33-38.

13. Лазерная техника и технология. В 7 кн. / под ред. А. Г. Григорьянц. - М. : Высш. шк., 1987. - Кн. 5.: Лазерная сварка металлов / А. Г. Григорьянц, И. Н. Шиганов. - 1988. - 206 с.

14. Забелин А. М., Оришич А. М. Чирков А. М. Лазерные технологии машиностроения. Новосибирск : Изд-во НГУ, 2004. - 156 с. 
open-aceess journal

15. Oliver W. C., Phar G. M. An improved technique for determining hardness and elastic modulus using load and displacement sensing indentation experiments // Journal of Materials Research. - 1992. - Vol. 7, iss. 6. - P. 1564-1583. - DOI: 10.1557/JMR.1992.1564.

16. Федосов С. А., Пешек Л. Определение механических свойств материалов микроиндентированием: Современные зарубежные методики. - М. : Физический факультет МГУ, 2004. $-100 \mathrm{c}$.

17. Bulychev S. I. Relation between the reduced and unreduced hardness in nanomicroindentation tests // Technical Physics. - 1999. - Vol. 44, iss. 7. - P. 775-781.

18. Структурная неоднородность сварного соединения алюминиевого сплава и моделирование его упругой деформации / С. В. Смирнов, Н. Б. Пугачева, М. В. Мясникова, Е. О. Смирнова // Физическая мезомеханика. - 2014. - № 1. - С. 51-56.

19. Пугачева Н. Б., Трушина Е. Б., Пугачева Е. И. Лазерная сварка титанового сплава Ti-5Al-2,5Sn // Вопросы материаловедения. - 2013. - № 2 (74). - С. 83-92. 